\title{
Undescended testis: importance of a timely referral to a surgical specialist
}

Su Jin Kim, MD

Department of Pediatrics, Inha University Hospital, Inha University College of Medicine, Incheon, Korea

\section{Key message}

Undescended testes (UDT) is the most common congenital genitourinary abnormality in male infants and associated with decreased fertility and a higher future malignancy risk, especially in cases of delayed orchiopexy after puberty. It is important to timely referral to a surgical specialist and timely surgical correction of UDT to improve fertility and decrease the risk of malignancy.

Undescended testes (UDT) is the most common congenital genitourinary abnormality in male infants and is diagnosed at birth in $1 \%-5 \%$ of full-term infants and up to $30 \%-45 \%$ of premature infants. ${ }^{1)}$ Most cases of UDT at birth correct spontaneously within the first 3 or 4 months of age; thereafter, spontaneous descent is rare. ${ }^{2)}$ UDT is classified as intraabdominal, inguinal, supra-scrotal, high scrotal, and scrotal according to their original position. Retractile testes and reascended testes (i.e., acquired UDT) require distinguishing from UDT. Retractile testes, unlike reascended testes, have completed the normal descent but may be pulled into the supra-scrotal area by the cremasteric reflex. The testes can then remain in a scrotal position, which are considered normal variants in a prepubertal boy. ${ }^{3)}$ Retractile testes maybe not associated with an increased risk of acute torsion, subfertility, and malignancy; however, they can reascend at a variable rate of $3.2 \%-32 \%$, which is considered abnormal. ${ }^{4,5)}$ Retractile testes should be followed up annually until the testes have clearly descended. Reascended testes are defined as testes that were originally in a scrotal position but then ascended and become undescended. ${ }^{1)}$ It is caused by the fibrosis of a patent processus vaginalis and inadequate spermatic cord growth. ${ }^{3)}$

History and careful inspection and palpation from the inguinal canal toward the pubis are essential to the diagnosis of UDT. Imaging studies including ultrasonography or magnetic resonance imaging are not recommended because they rarely aid decision-making and treatment policy.6) Inguinal hernia, a higher risk of testicular torsion, and testicular trauma are potential complications of UDT. UDT are also associated with decreased fertility and a higher future malignancy risk despite surgical correction, especially in cases of delayed orchiopexy after puberty. UDT disrupt the differentiation of primitive germ cells to the spermatogonia and increase the risk of lower counts and poorer sperm quality. ${ }^{7)}$ Subfertility severity may be increased with bilateral UDT and a long duration of a supra-scrotal position. Arrested gonocyte in UDT can be a risk factor for the development of testicular germ cell tumors after puberty; early surgical intervention such as orchiopexy is known to decrease the risk of testicular cancer but does not completely eliminate it. ${ }^{8)}$ Routine long-term follow-up of patients with orchiopexy is not needed, but screening and self-examination of the testes after puberty is recommended to aid in early cancer detection. ${ }^{6,9)}$

International guidelines for UDT from the American Urological Association (AUA) ${ }^{6}$ and European Association of Urology ${ }^{9}$ ) do not recommend hormone therapy because of a lack of evidence and ineffectiveness. UDT is almost always managed surgically, which is clearly proven beneficial for increasing fertility and decreasing cancer risk. In a recent issue of Clinical and Experimental Pediatrics, Shin and Jeon ${ }^{10)}$ published a review article entitled "Diagnostic and treatment guidelines for undescended testis." This article describes the diagnosis, differential diagnosis, hormone therapy, fertility, risk of testicular cancer, and timing of surgical therapy of UDT based on international guidelines. Shin and Jeon ${ }^{10)}$ suggest timely referral to a surgical specialist and timely surgical correction of UDT to improve fertility and decrease the risk of malignancy. Primary caregivers including general pediatricians should consider the following indications for referral: (1) the testis has not descended into the scrotum by 6 months of age, (2) newly diagnosed UDT after 6 months of age, or (3) suspected testicular torsion. In addition, the AUA guidelines recommend indications for referral to a surgical specialist or multidisciplinary team as follows: (1) bilaterally nonpalpable testes, (2) bilaterally or unilaterally nonpalpable testis with hypospadias or suspected disorder of sex development, (3) difficulty differentiating among undescended, retractile, and ectopic testes. ${ }^{6}$ Shin and Jeon ${ }^{10)}$ insisted that the original location of the UDT and age at orchiopexy are impor-

Corresponding author: Su Jin Kim, MD. Department of Pediatrics, Inha University Hospital, Inha University College of Medicine, 27 Inhang-ro, Jung-gu, Incheon 22332, Korea 


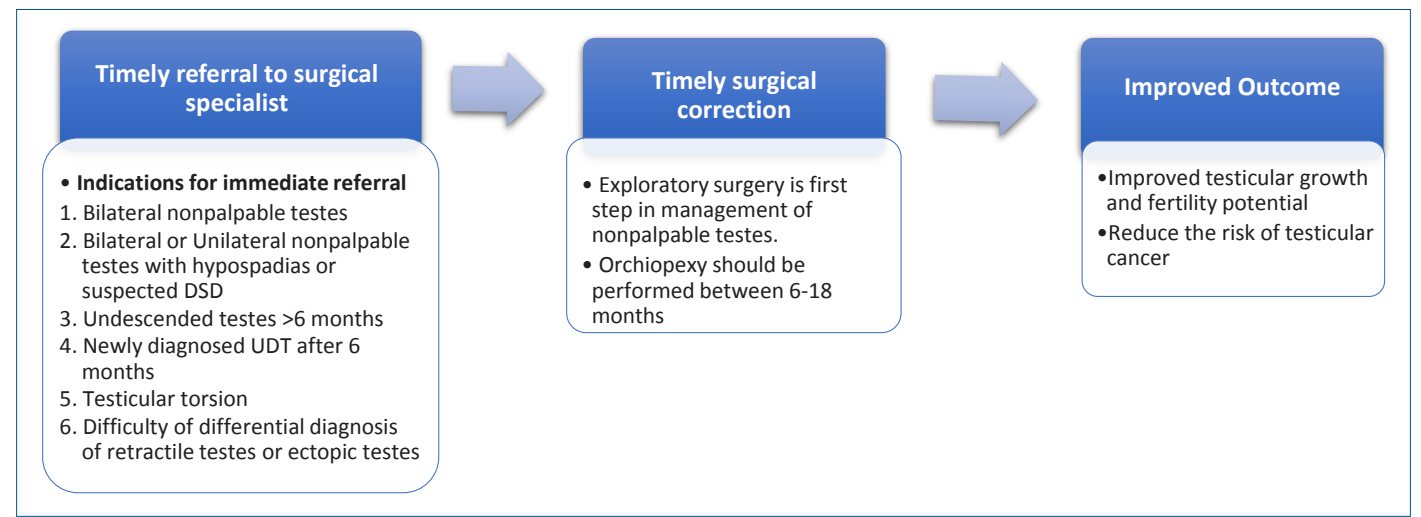

Fig. 1. The importance of a timely referral for and indications of an immediate consultation or referral to a surgical specialist for undescended testes. DSD, disorder of sex development; UDT, undescended testes.

tant factors in the prediction of fertility potential and future malignancy risk. Thus, orchiopexy is recommended between 6 and 18 months at the latest based on international guidelines. In conclusion, this review by Shin and Jeon ${ }^{10)}$ describes the importance of a timely referral and indications for referral to a surgical specialist for UDT. However, it would be better if Shin and Jeon ${ }^{10)}$ mentioned Korean data about UDT in this review. Fig. 1 demonstrates the factors related a timely referral to a surgical specialist and timely surgical correction of UDT.

\section{Conflict of interest}

No potential conflicts of interest relevant to this article are reported.

See the article "Comparison of diagnostic and treatment guidelines for undescended testis" via https://doi.org/10.3345/ cep.2019.01438.

\section{References}

1. Barthold JS, Gonzalez R. The epidemiology of congenital cryptorchidism, testicular ascent and orchiopexy. J Urol 2003;170:2396-401.

2. Wenzler DL, Bloom DA, Park JM. What is the rate of spontaneous testicular descent in infants with cryptorchidism? J Urol 2004;171:84951.
3. Keys C, Heloury Y. Retractile testes: a review of the current literature. J Pediatr Urol 2012;8:2-6.

4. Agarwal PK, Diaz M, Elder JS. Retractile testis--is it really a normal variant? J Urol 2006;175:1496-9.

5. Stec AA, Thomas JC, DeMarco RT, Pope JC 4th, Brock JW 3rd, Adams MC. Incidence of testicular ascent in boys with retractile testes. J Urol 2007;178:1722-4; discussion 4-5.

6. Kolon TF, Herndon CD, Baker LA, Baskin LS, Baxter CG, Cheng EY, et al. Evaluation and treatment of cryptorchidism: AUA guideline. J Urol 2014;192:337-45.

7. Schneuer FJ, Milne E, Jamieson SE, Pereira G, Hansen M, Barker A, et al. Association between male genital anomalies and adult male reproductive disorders: a population-based data linkage study spanning more than 40 years. Lancet Child Adolesc Health 2018;2:736-43.

8. Pettersson A, Richiardi L, Nordenskjold A, Kaijser M, Akre O. Age at surgery for undescended testis and risk of testicular cancer. N Engl J Med 2007;356:1835-41.

9. Radmayr C, Bogaert G, Dogan HS, Kočvara R, Nijman JM, Stein R, et al. EAU Guidelines on Paediatric Urology 2018. Arnhem (The Netherlands): European Association of Urology, European Society for Paediatric Urology, 2018.

10. Shin J, Jeon GW. Comparison of diagnostic and treatment guidelines for undescended testis. Clin Exp Pediatr 2020 [Epub]. https://doi.org/ 10.3345/cep.2019.01438.

How to cite this article: Kim SJ. Undescended testis: importance of a timely referral to a surgical specialist. Clin Exp Pediatr 2020;63:429-30. https://doi.org/10.3345/cep.2020.00115. 